\title{
Fluid Switch For Radiation Pattern Reconfigurable Antenna
}

\author{
Linyu Cai \\ Dept. Electronic and Electrical Engineering \\ University College London \\ Torrington Place, London WC1E 7JE, UK \\ uceecai@ucl.ac.uk
}

\begin{abstract}
This work presents a conductive fluid switch design, which is applied to a 3 elements Yagi-Uda antenna operating at $433 \mathrm{MHz}$ industrial scientific medical (ISM) band. The directivity of the antenna is re-configurable by controlling conduction state of the fluid switch. 3D printing technology is used to manufacture the two parasitic elements. A microcontroller and a pump system are used to control the fluid level in the switch.
\end{abstract}

Key words-Reconfigurable, fluid switch, 3D-printing,YagiUda antenna

\section{INTRODUCTION}

A Yagi-Uda antenna basically consists of an active element and two additional parasitic elements, which are termed as director or reflector, respectively [1]. It is widely used as a high-gain antenna in ultra high frequency (UHF) band[1]. Yagi-Uda antenna has a directional narrow radiation beam and is suitable for various applications if the radiation direction of the antenna can be re-configured. In this work, the performance of fluid switches will be evaluated on a Yagi-Uda antenna for the purpose of direction configuration.

Fluid has many advantages on antenna applications such as re-configurable radiation performance by controlling the shape of the fluid. A previous study gave a design of frequency-reconfigurable antenna with metal fluid [2]. Diodes are also commonly used to re-configure antenna performance[3].This work demonstrates a conductive fluid switch in Polydimethylsiloxane (PDMS) circular tube, which can change the radiation direction of a Yagi-Uda antenna by adjusting the fluid level in the PDMS tube.

The proposed Yagi-Uda antenna operates at $433 \mathrm{MHz}$ ISM frequency band has $3.9 \mathrm{dBi}$ gain and $3 \mathrm{~dB}$ beam width of $130.8^{\circ}$. The radiation direction of the antenna is able to be re-configured by using the conductive fluid switches. Therefore, different radiation performance can be achieved via switching on or off different parasitic elements of the antenna. A "Form $1+$ " high resolution 3D printer [4] was used for the fluid tube fabrication. CST microwave studio 2016 was used to simulate the antenna performance[5].

\section{ANTENNA GEOMETRY}

The geometry of the proposed fluid Yagi-Uda antenna is shown in Fig. 1. The antenna consists three main parts: 1. a square ground plane. 2. an active monopole antenna. 3. two

\author{
Kin-Fai Tong \\ Dept. Electronic and Electrical Engineering \\ University College London \\ Torrington Place, London WC1E 7JE, UK \\ k.tong@ucl.acl.uk
}

parasitic metal wires supported by the PDMS circular tubes. The dimensions of the ground plane is $(\mathrm{L} \times \mathrm{W} \times \mathrm{h}) 250 \times 250 \times 0.1$ $\mathrm{mm}^{3}$; the active quarter wavelength monopole antenna is located in the center of ground plane, which has the length of $155 \mathrm{~mm}$ (equal $0.238 \lambda$ ); The monopole antenna is fed by a coaxial cable, which is on the back side of the ground plane. Two 3D-printed PDMS tubes, which supported the two parasitic elements, are located in the diagonal of the ground plane symmetrically. The two parasitic wires are able to work as a director or a reflector by controlling the fluid level in PDMS tube. PDMS is a low cost commercially available silicone based rubber, [6] which has loss tangent $(\tan \delta)$ of 0.001 and dielectric constant $\left(\varepsilon_{\mathrm{r}}\right)$ of 82 [7]. It is manufactured by the stereolithography (SLA) 3D printing technology. Thus, it is possible to create high accuracy and low leakage fabrication with very low cost. The conductive fluid inside the PDMS circular tube is potassium chloride solution (KCL) of $2 \mathrm{~mol}$ density. The $2 \mathrm{~mol} \mathrm{KCL}$ solution has the dielectric constant $\left(\varepsilon_{\mathrm{r}}\right)$ of 76 conductivity $(\sigma)$ of $20 \mathrm{~S} / \mathrm{m}$ at $\mathrm{sub}-\mathrm{GHz}$ frequency band [7].

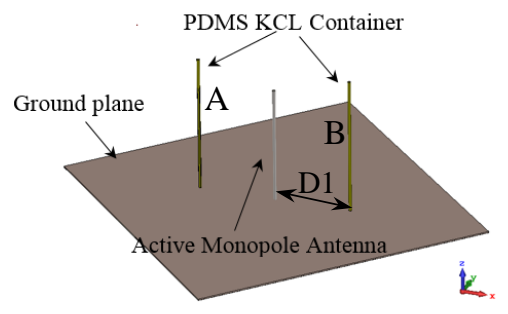

Fig. 1. The proposed Yagi-Uda antenna with fluid switches.

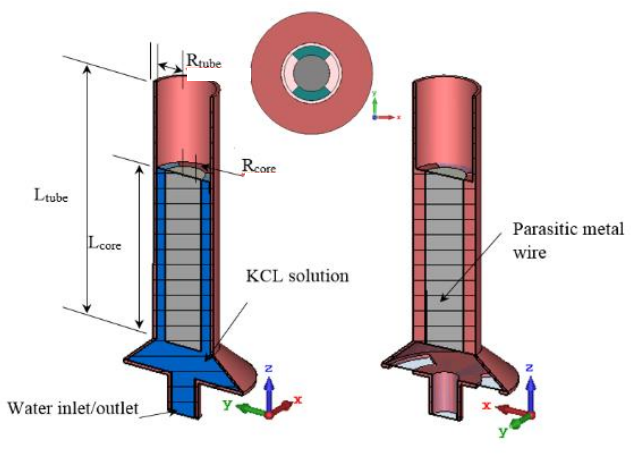

1. With KCL solution 2. Without KCL solution Fig. 2. PDMS container construction (xz plane, yz plane cross-sectional views and topview) 


\section{A. PDMS Container Construction}

Fig. 2 shows the cross-sectional views of xz plane and yz plane as well as the top view of fluid level adjustable construction. The KCL solution is injected from the bottom. The structure consists of two different parts: the center metal wire and the PDMS container used to fix and separate the metal wires from the ground plane. It has a hollow structure on the bottom, which provides electrical connection with antenna ground when KCL solution is pumped in.

\section{B. Operation mechanisum}

A mini water pump is used to connect the bottom of the PDMS container. the fluid level can be adjusted in submillimeter scale by controlling the pump pressure.

Configuring the three different fluid levels in the PDMS tube can obtain three different operating states of the parasitic elements. State 1: There is no KCL solution in the PDMS tube, the parasitic metal wire inside the tube is disconnected from the ground. The parasitic metal wire will become director as the length of the core is shorter than $\lambda / 4$. State 2: When pumping the KCL solution into the tube to the fluid level being higher than the bottom of the center parasitic metal wire, the wire will be connected to the antenna ground leading to a reflector. State 3: The fluid level is higher than the top surface of the wire. In this scenario, the electrical length of the wire is changed within the fluid level, which can be used for fine adjustment of the radiation performance. Configuring different operating states of parasitic wire fluid switch, direction radiation of antenna can be achieved.

TABLE 1 DRIVEN ELEMENT

\begin{tabular}{|l|l|l|l|}
\hline Size & \multicolumn{1}{|c|}{ Parameters } & Symbols & Dimensions \\
\hline \multirow{2}{*}{$\begin{array}{c}\text { Driven } \\
\text { element }\end{array}$} & Length of the copper cylinder & $\mathrm{L}_{\text {Driven }}$ & $165 \mathrm{~mm}$ \\
\cline { 2 - 4 } & Radius of the driven element & $\mathrm{R}_{\text {Driven }}$ & $1.2 \mathrm{~mm}$ \\
\hline \multirow{4}{*}{$\begin{array}{l}\text { Passive } \\
\text { elment }\end{array}$} & Length of the tube & $\mathrm{L}_{\text {tube }}$ & $180 \mathrm{~mm}$ \\
\cline { 2 - 4 } & Radius of the tube (outside radius) & $\mathrm{R}_{\text {tubeout }}$ & $1.8 \mathrm{~mm}$ \\
\cline { 2 - 4 } & Radius of the tube (inside radius) & $\mathrm{R}_{\text {tubein }}$ & $1.6 \mathrm{~mm}$ \\
\cline { 2 - 4 } & Length of the parasitic metal wire & $\mathrm{L}_{\text {coil }}$ & $155 \mathrm{~mm}$ \\
\cline { 2 - 4 } & Radius of the parasitic metal wire & $\mathrm{R}_{\text {coil }}$ & $1.2 \mathrm{~mm}$ \\
\cline { 2 - 4 } & Separation from the ground center & $\mathrm{D} 1$ & $100 \mathrm{~mm}$ \\
\hline
\end{tabular}

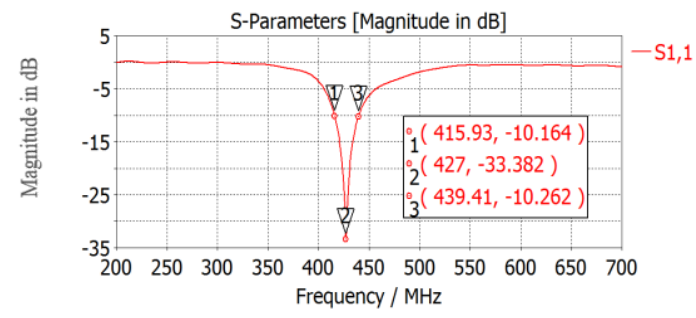

Fig. 3. $\mathrm{S}_{11}$ of the proposed Yagi-Uda antenna in Stage 2.

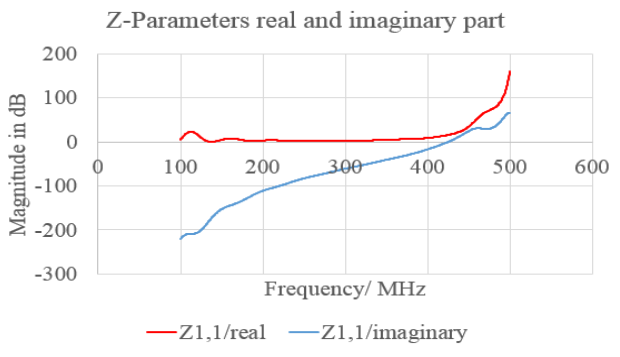

Fig. 4. $Z_{11}$ of the proposed Yagi-Uda antenna in Stage 2.
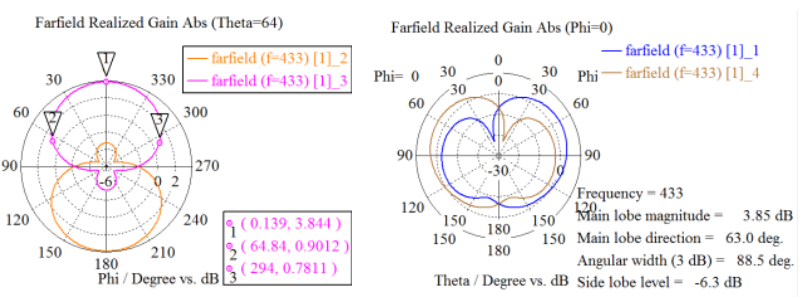

Fig 5. Radiation patterns(2D)

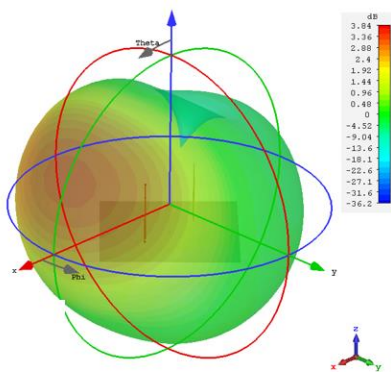

\begin{tabular}{|c|l|}
\hline Type & Farfield \\
\hline Frequency & $433 \mathrm{MHz}$ \\
\hline Output & Realized Gain \\
\hline Rad.effic & $-0.8817 \mathrm{~dB}$ \\
\hline Tot.effic & $-0.9126 \mathrm{~dB}$ \\
\hline Rizd.Gain & $3.840 \mathrm{~dB}$ \\
\hline
\end{tabular}

Fig. 6. Radiation patterns(3D)

\section{RESULTS DISCUSSION}

The simulated $S_{11}$ of state 2 is showed in Fig. 3, the operating bandwidth is from $419.3 \mathrm{MHz}$ to $443.6 \mathrm{MHz}$. Results in Fig. 4 indicate that the antenna resonates at $430.1 \mathrm{MHz}$. Fig. 5 shows the radiation pattern of the proposed antenna when theta equals $63^{\circ}$. When switching on PDMS tube A and $\mathrm{B}$ respectively, the radiation beam points opposite direction. At both directions, a maximum realized gain of $3.84 \mathrm{dBi}$ and $130.8^{\circ} 3 \mathrm{~dB}$ beam width are obtained. Therefore, we predict that the proposed fluid switch Yagi-Uda antenna can points at different azimuth directions when the corresponding parasitic wires are installed.

\section{CONCLUSION}

A 3-elements fluid switch Yagi-Uda antenna was designed and simulated at $433 \mathrm{MHz}$ ISM band. More parasitic elements will be added in future work to obtain higher gain and multiple main beam directions.

\section{REFERENCE}

[1] G. R, Modern Dictionar of Electronics. 1999.

[2] G. J. Hayes, J.-H. So, A. Qusba, M. D. Dickey, and G. Lazzi, "Flexible Liquid Metal Alloy (EGaIn) Microstrip Patch Antenna," TAP_IEEE Trans. Antennas Propag., vol. 60, no. 5, pp. 2151-2156, 2012.

[3] J. Costantine, Y. Tawk, S. E. Barbin, and C. G. Christodoulou, "Reconfigurable antennas: Design and applications," Proc. IEEE, vol. 103, no. 3, pp. 424-437, 2015.

[4] “Formlabs User Manual," vol. 12, 2008.

[5] “CST Microwave studio," IEEE Microw. Mag., vol. 7, no. 4, pp. 11-11, 2006.

[6] K. F. Tong, C. B. Fortuny, and J. Bai, "Low cost 3D-printed monopole fluid antenna," 2015 Int. Symp. Antennas Propag., pp. 1-4, 2015.

[7] C. Borda-Fortuny, K. F. Tong, A. Al-Armaghany, and K. K. Wong, "A Low-Cost Fluid Switch for Frequency-Reconfigurable Vivaldi Antenna," IEEE Antennas Wirel. Propag. Lett., vol. 16, pp. 3151-3154, 2017. 